\title{
Oral Fossilization of College Students in English Acquisition
}

\author{
Liu Xiaoyi \\ Foreign Language Department \\ Jilin Business and Technology College \\ Changchun, China \\ 182076127@qq.com
}

\begin{abstract}
Interlanguage fossilization is a universal phenomenon in second language acquisition. In view of the interlanguage fossilization phenomenon in college students' oral English teaching in higher vocational colleges, this paper explores the causes of the students oral English fossilization from students' perspective and teachers' perspective and then puts forward four measures, respectively training language basic skills and cultivating consciousness of pronunciation and grammar, making a balance in the input and output of language, providing appropriate emotional feedback and raising students' psychological quality and including target language culture and minimizing the interference of mother tongue. Thus, the oral English fossilization in oral English of college students can be greatly alleviated or avoided.
\end{abstract}

Keywords-Fossilization; College students; Oral English teaching

\section{INTRODUCTION}

In 2000, the ministry of education issued "The higher vocational English teaching basic requirements" and stressed "give priority to, practice for a sufficient degree" as the teaching policy, paying attention to cultivating the students' communicative competence, the main aspect of which is embodied as students' ability of oral communication. Oral English teaching for a long time has been the weakest link in higher vocational English teaching, and most of the students in vocational college limit oral English to simple words and sentence patterns, the spoken language ability stays in a state of fossilization. How to change students' oral fossilization is a problem to be solved urgently in higher vocational English teaching, therefore, to explore the causes of fossilization and adopt corresponding teaching countermeasures is possible to mitigate and reduce the fossilization and effectively improve the students' ability of oral communication.

So far, researches on oral language fossilization in our country's academic circles are still relatively fewer than the foreign researches, especially in the field of foreign language fossilization. However, these foreign language learners are shouldering the major task of our country in foreign exchange and communication (Qi Weijun, 2010). Their foreign language level not only affects their own development, but also reflects the international status of citizens in our country to some extent, so the research on foreign language fossilization is of farreaching significance. Therefore, the author hopes to fill the blank of fossilization research with individual power through the analytic research on college students' oral fossilization phenomenon and analysis of the causing factors, and puts forward relevant teaching countermeasures, expecting to be concerned by academic circles in this area.

\section{INTERLANGUAGE AND FOSSILIZATION}

In the process of second language acquisition, an important concept-inter-language will emerge, which was put forward by the famous British linguistic Larry Selinker (1972). It refers to a language system between the target language and the learner's mother tongue, in which both success and failure could coexist and progressed as the target language input (Selinker, 209-231)[1]. Inter-language has both the features of target language and native language but is neither. Selinker also initiated a new definition-- fossilization to explain the mistakes that repeated in learner's inter-language again and again.

Since Selinker put forward the definition of fossilization in 1972, Selinker asserted that about 95\% of L2 learners failed to reach their L2 to the level of native speakers. The failure to attain the fully competence of second language was defined as "partial-outcome" (David, 92). Selinker defined this phenomenon as fossilization at the very beginning: The longterm persistence of plateaus of non-target-like structures in the inter-language of non-native speakers (Selinker\& Lamendella, 124)[2].

As learners progress towards target language, learners may conquer the problem of fossilization once in a while by expressing in the standard target language, but as they are apt to focus on the "meaning", especially when the L2 production requires expressing some more complex subject matters. Rod Ellis defined this phenomenon as "Black sliding” (Ellis, 135) [3].

From all the above mentioned, fossilization can be defined as a phenomenon that leads to the freezing of second language learners' inter-language.

\section{PREVIOUS Studies ON ORAL ENGLiSH FossiLIZATION AT HOME AND ABROAD}

Fossilization has been viewed as a phenomenon which emerges and develops in second language acquisition. 
Researchers have been interpreting and explaining it differently from different study fields. From 1970s to 1990s, the study of fossilization mainly focused on theoretical explanation, several kinds of different theories or models of fossilization have been proposed. In 1972, Selinker proposed a hypothesis about the five psycholinguistic process of fossilization, namely, native language transfer, transfer of training, strategies of communication, strategies of learning and overgeneralization of TL rules. Despite the psychological explanation proposed by Selinker, there are also biological causes of fossilization. Lenneberg and Lemendella can stand as the representatives in this field. In the year 1967, Lenneberg proposed the Critical Period Hypothesis, which states that the loss of neural plasticity is the main reason leading to the failure of L2 acquisition. While there is also another view that only the pronunciation has the critical period. (Scovel 101) And the critical period is essential to L2 acquisition. (Long 266) Later on, the fossilization has been viewed from a socialpsychological perspective. In 1978, Schumann established the Acculturation Model. According to him, acculturation is the process in which the changes in the language, culture and system of values of a group happen through interaction with those of the target language group. In recent years, some researchers tried to provide a wider scope of study in order to explore the new explanation. Multiple effects principle (MEP) is one of their products (Selinker\& Lakeshamanan 129). The MEP means that more than one SLA factors can contribute to possible fossilization.

While at home, the study of fossilization is relatively later than foreign countries. Due to the opening-up and reform policy, we deepened our communication with outside world, thus the second language teaching and learning are more and more stressed.

$\mathrm{Hu}$ Rong summarized the fossilization research in recent years and argued that fossilization is more an underlying cognitive process or mechanism than simply a product of language use, stressing that a genuine explanation has taken into consideration the influence of various attributing factors and their interactions. And Li Qiaolan sampled the natural spoken language data from immediate and advanced Chinese learners and the native speakers. After the analysis of date and made a comparison between them, she discovered the Chinese learners could not achieve the same language as native speakers. Without doubt, her study demonstrated the pragmatic fossilization should not be ignored in the EFL teaching and learning process. All the studies mentioned above enlightened both English teachers and learners a lot.

\section{CAUSES OF ORAL ENGLiSH FOSSILIZATION IN HigHER VOCATIONAL SCHOOL}

Linguists both at home and abroad explained interlanguage fossilization from the perspective of all levels. In 1972, Selinker proposed a hypothesis about the five psycholinguistic process of fossilization, namely, native language transfer, transfer of training, strategies of communication, strategies of learning and overgeneralization of TL rules. However, what are the causes of oral English fossilization among college students in higher vocational schools. This paper, according to the teaching situation and practice in higher vocational schools in recent years, summarizes the following reasons from students and teachers' perspective.

The author, in the light of the analytic method in "Research on coping strategies of Chinese learners' foreign language teaching from oral fossilization perspective” by Jiang Xiaofeng(Jiang Xiaofeng, 2012) and according to the percentage rank of each parameter from the least to the greatest, presents the distribution of reasons for oral English fossilization in Table 1 as follows[4].

TABLE I. DEGREE OF ORAL ENGLISH FOSSILIZATION

\begin{tabular}{|c|c|c|}
\hline Parameter & Rank & Degree Of Fossilization(Per Capita) \\
\hline speaking speed & 1 & $50.00 \%$ \\
\hline pronunciation and intonation & 2 & $47.62 \%$ \\
\hline sentence making difficulty & 3 & $45.24 \%$ \\
\hline rhythm processing & 4 & $38.10 \%$ \\
\hline cohesion and coherence & 5 & $35.71 \%$ \\
\hline context processing & 6 & $33.33 \%$ \\
\hline inflexion of the verb & 7 & $28.57 \%$ \\
\hline word order & 8 & $21.43 \%$ \\
\hline phrases and collocations & 9 & $9.52 \%$ \\
\hline
\end{tabular}

According to research result of relevant theories, it is easy to figure out the reasons for college students' oral English fossilization phenomenon among college learners.

From Table 1, it is evident that speaking speed, pronunciation and intonation, and sentence making difficulty rank the top three degrees of oral English fossilization. That is to say, currently, among all the obstacles in the process of oral English acquisition, college English learners are mainly faced with these three factors.

\section{A. Students' perspective}

\section{1) The interference of emotional factors}

According to Krashen's affective filter hypothesis, the success of second language acquisition depends largely on the learner's three kinds of emotional factors: motivation, interest, self-confidence and anxiety. Negative factors will lead to a great effect on the occurrence of fossilization. Interest is the inner motive and power to promote learning. A lot of higher vocational college students in the process of learning English are faced with great frustration. They feel it difficult to understand English and communicate with others in English, which is known as the so-called "deaf English" or "dumb English”, so they have lost interest and confidence in English learning. Their motivation of learning English is to take the distinction and lack of communication desire for oral English which has nothing to do with the distinction. Most students always suffer a kind of psychological fear and inferiority complex when they are allowed to speak English in public, because they are afraid of making mistakes and dare not speak. Using English and Chinese languages at the same time forms the psychological barrier on the other hand, which seriously hinders the development of college students' oral 
communication ability. In addition, some teachers cannot put up with the mistakes made by students when they are speaking English and must rectify mistake immediately, which may hurt students' self-esteem and fragile feelings of foreign language learning and make students suffer from emotional disorders, further leading to the development of interlanguage and fossilization.

\section{a) Negative transfer of native language}

Interference of native language is also known as negative transfer. Students are prone to the phenomenon of negative transfer of native language, such as to deduce the pronunciation of a foreign language in their native language' tone and rhythm, resulting in slow speaking speed, phoneme misuse, nasal defect, and even the phenomenon such as reading ability defect.

Interference of mother tongue in oral English learning is mainly manifested in two aspects:

\section{b) Voice.}

The interference of mother tongue pronunciation and dialects are the main factors of phonetic fossilization. Most students mispronounce the basic phonemes, such as inaccurate pronunciation of vowels and consonants and lack of consciousness of pronunciation and intonation. The mispronunciation wasn't timely corrected, fixed for a long time and finally formed the fossilization. For example, some students in oral English often pronounce "I think" as "I sink", leading to the listener's confusion and misunderstanding. These wrong pronunciations and intonations affect the actual communication.

\section{c) The habits of thinking.}

Language and thinking are related to each other closely. The difference in language expression is generally caused by various thinking modes. Many students often speak English using the thinking mode of Chinese, which is not in conformity with the English expression. This is commonly known as "Chinglish" phenomenon. Sometimes, when letting others firstly enter the door, some students according to the communication habit of Chinese are used to saying "You go first, please". However, the idiomatic English expression is "After You". They completely translate word for word according to the Chinese thinking habit and do not conform to the English expression, which reflects the differences of thinking in Chinese and English and becomes one of the main sources of fossilization phenomenon.

\section{B. From teaching perspective}

Not all foreign language teachers can make the students learn a foreign language successfully. Cai Longquan (2003) pointed out that the teacher speaks too much, it is bound to cover students' chance to speak; if the teacher speaks lacking of change, it is bound to limit the scope of students' language contact and imitation and if the teacher speaks in the wrong time, it is bound to inhibit students' desire to speak. Therefore, the negative effect from teachers is evident. According to empirical observation, the main teaching factors leading to the participants' oral English fossilization phenomenon are the low quality of language input and the inefficiency of classroom teaching behavior.
First of all, students, if hear wrongful or inaccurate English expression in the classroom time, it may deepen their wrong understanding of the target language and make them involve into a vicious circle. There is no denying the fact that the foreign language teachers' oral English level is generally low in our country to compare with native English speakers' language level. However, teachers' oral English output is the main source in the process of students' foreign language acquisition. Passive exposure to the input source will easily lead to oral fossilization.

Second, when the teaching object is limited to those college learners who have good writing level, we found that: (1) the teacher's teaching behavior to get separated from the context of some words or phrases and require students to make the same feedback immediately to the context at the same time will force students to generate fossilized structures and inter-language; (2) many teachers tend to blindly move into the next phase of the teaching before ensuring that the students have highly realized and accepted their corrective actions to oral mistakes, as a consequence, students haven't truly taken into the corrected content and transferred it into their inter-language system; (3) the teachers' feedback in itself is not correct, further leading to students' more serious mistakes.

\section{STRATEGIES EXPLORATION TO SOLVE ORAL FOSSILIZATION}

Although it is difficult to avoid interlanguage fossilization, English teachers can delay the occurrence of fossilization to some extent or avoid fossilization permanently if they take corresponding teaching measures according to the root causes of fossilization and actual situation of college students' oral English.

\section{A. Strengthen the training of language basic skills and cultivation of consciousness of pronunciation and grammar}

Speech is the necessary premise to learn language, which will directly influence the improvement of learners' oral English ability. The teacher are supposed to teach students the necessary knowledge of voice, train students the skills of voice tone, liaison and stress and make them master the correct pronunciation principle and accurate pronunciation skills to master the correct pronunciation. At the same time, strengthening the training of listening skills can enable students not only to acquire the standard English pronunciation, but also to cultivate their distinguishing ability of sound and good English language sense, eliminating obstacle in speaking and listening, enhancing their confidence in speaking and finally breaking the state of fossilization.

\section{B. Appropriate input and output of language}

Karashen's "input hypothesis” thinks that only contacting with a large amount of comprehensible input, language acquisition is able to occur. Appropriate language input refers to the difficulty of the input is slightly higher than the language level of learners. Otherwise, fossilization is likely to occur to language learners in the process of acquisition. Teachers should make full use of the intuitive image and rich information features of multimedia to create a real language input 
environment and communication atmosphere for students, enhance the interest and diversity of language input, and make a reasonable design of teaching goal, so as to make language input close to the language level of students and promote interlanguage to move closer to the target language. Only through output can English teachers find students' interlanguage and provide timely feedback to help them correct language errors, so language output plays an important role in the development of interlanguage. Teachers should change the traditional teaching idea and focus on students' demand, thus a multiple communication between teachers can provide students with more opportunities for oral English output. Through a variety of ways to promote the output of language, students' desire and courage to express them in English can be aroused and formation of the language habits can be promoted, so as to minimize and avoid the occurrence of fossilization.

\section{Provide appropriate emotional feedback and raises students' psychological quality}

Teachers are not only an imparter of knowledge, but also can guide students' physical and mental health development. Compared with the general undergraduate students from college, students from higher vocational schools have a weak foundation in English, so their learning enthusiasm is not high and confidence is not strong. Teachers in oral English teaching should suit the characteristics of higher vocational students and apply emotional factors in classroom teaching, giving students more affirmation and encouragement, stimulate students' learning motivation and create a harmonious and pleasant classroom environment, so as to eliminate nervousness and anxiety of students in the class.

Teachers are supposed to deal with students' language errors with a tolerant attitude and a positive point of view and let students understand the errors produced in foreign language acquisition are an inevitably natural phenomenon, so as to enhance students' confidence. They should also pay attention to correction strategy of students' errors, extreme practice will finally because student's psychological and social pressure, lead to the development of interlanguage and form the fossilization phenomenon. On the other hand, any one of the students' language output is also the language output of the whole class. If the error is not timely corrected, it could be mistaken as a correct expression, in this way, a student's individual fossilization will turn into groups fossilization. Teachers are also supposed to build a relaxed and pleasant classroom atmosphere. According to different causes of fossilization, different methods and measures should be taken to consider correcting students' mistakes in time, making students realize the error and avoiding hurting their self-esteem, thus, the anxiety of students can be eliminated and their adverse emotional infiltration can be reduced. Gradually, students will overcome the psychological barriers of oral English expression.

\section{Input target language culture and minimize the interference of mother tongue}

The goal of higher vocational English teaching is to cultivate and improve students' communicative competence, and an important feature of their communicative competence is that students can express appropriately according to the topic, context and cultural background in the communication. In order to realize communicative functions of language, in addition to mastering certain language knowledge, students must be familiar with and understand culture connotation and background knowledge carried by the language. Only combining cultural learning and language teaching, college students can better understand and learn the target language culture. The deeper they understand the target language culture, the less pragmatic failures they will make and the stronger pragmatic competence they will attain. At the same time, they can deeply understand the target language and effectively avoid fossilization. Teachers should introduce background knowledge combining the text, explain cultural connotation conveyed by word collocation combining vocabulary and pay attention to the cultivation of contextual, pragmatic and crosscultural awareness, so that students can input target language culture through various channels, broaden their cultural vision and strengthen their sensitivity to cultural differences between English and Chinese.

\section{CONCLUSION}

To sum up, interlanguage fossilization is a common phenomenon in students' English learning process and is the result of the interaction of various factors. Interlanguage fossilization is a major factor hindering the development of the students' oral communication ability. To study the reasons and take reasonable teaching strategy in the process of teaching has a certain practical significance in changing the current status of oral fossilization of college students, improving the oral English teaching environment and the level of oral English teaching.

\section{REFERENCES}

[1] Selinker, L. Interlanguage [J]. International Review of Applied Linguistic Language, Teaching , 1972, (10): 201-231.

[2] Selinker, L. Rediscovering Interlanguage[M]. London: Longman. 1992, $8(3)$

[3] Ellis, R. The study of Second Language Acquisition[M].Shanghai Foreign Language Education Press, 1994. 302

[4] Shi Wentao. Oral English interlanguage fossilization[J]. Journal of Civil Aviation Flight University of China, 2009( 3) : 60-62 